\title{
Applicability of activated carbon obtained from peach stone as an electrochemical sensor for detecting caffeine
}

\author{
J.J. Arroyo-Gómez ${ }^{\mathrm{a}, *}$, D. Villarroel-Rocha ${ }^{\mathrm{a}}$, K.C. de Freitas-Araújo ${ }^{\mathrm{b}}$, Carlos A. Martínez-Huitle ${ }^{\mathrm{b}, \mathrm{c}}$, \\ K. Sapag \\ ${ }^{a}$ Laboratorio de Sólidos Porosos (LabSoP), INFAP-CONICET, Universidad Nacional de San Luis, Av. Ejército de los Andes 950, 5700 San Luis, Argentina \\ b Laboratório de Eletroquímica Ambiental e Aplicada (LEAA), Instituto de Química, Universidade Federal do Rio Grande do Norte, CEP 59072-970, Natal, Brazil \\ ${ }^{\mathrm{c}}$ Unesp, National Institute for Alternative Technologies of Detection, Toxicological Evaluation and Removal of Micropollutants and Radioactives (INCT-DATREM), \\ Institute of Chemistry, P.O. Box 355, 14800-900 Araraquara (SP), Brazil
}

\section{A R T I C L E I N F O}

\section{Keywords:}

Activated carbon

Electrochemical sensor

Caffeine

\begin{abstract}
A B S T R A C T
Simple, economical and highly sensitive electrodes for the detection of caffeine by using activated carbon from peach stones have been developed. The activated carbons were synthesized by chemical activation using $\mathrm{ZnCl}_{2}$ and $\mathrm{ZnCl}_{2}: \mathrm{FeCl}_{3}(1: 1)$ as chemical agents, producing carbons with different textural properties and morphologies, which led to differences in the electroactive area of the materials that affected the electrochemical response to caffeine. The electrodes presented a linear response in the concentration range from $3.98 \times 10^{-5}$ to $4.58 \times 10^{-4}$ and $6.37 \times 10^{-4} \mathrm{M}$ for the carbon activated with $\mathrm{ZnCl}_{2}$ and $\mathrm{ZnCl}_{2}: \mathrm{FeCl}_{3}(1: 1)$, respectively. The detection limits were estimated in $2.85 \times 10^{-5}$ and $1.60 \times 10^{-5} \mathrm{M}$. The electrodes were tested to measure caffeine in real life samples, giving caffeine concentrations close to the reported values. Despite presenting the lowest surface area and the lowest thermal stability, the activated carbon obtained with $\mathrm{ZnCl}_{2}: \mathrm{FeCl}_{3}(1: 1)$ was more sensitive to caffeine, measuring caffeine concentrations very close to the reported values for the tested beverages. These results show that these electrodes may be an alternative to develop new and reliable analytical tools at low cost with high efficiency.
\end{abstract}

\section{Introduction}

Caffeine (1, 3, 7-trimethylpurine-2,6-dione) is reported as the most widely consumed stimulant; used in beverages, foods, pharmaceuticals, etc. This molecule is produced by $>60$ plants located in the tropical zone (both north and south of the equator), with caffeine contents ranging from $0.2 \%$ to $5.0 \%$ (mass percent on dry basis) [1]. In plant biology, caffeine is a secondary metabolite used for environmental adaptation, such as protection against depredators, growth prevention of competing seeds on the same ground, and incentive to pollinators [1]. In humans, the effect of caffeine depends on several factors (dose, body weight, individual response). At low doses, caffeine affects most of the body; stimulating tissue and organ activity, including the central nervous system [2]. This impacts both physical (endurance, performance, muscle strength, and pain tolerance), and cognitive functions (attention, vigilance, response time, memory, reasoning, decisionmaking, judgment, and risk-taking) [3]. On the other hand, at higher doses, caffeine produces anxiety, nausea, and nervousness. However, there are few cases reported on death by excessive caffeine consumption [2]. Due to its use in food and pharmaceutical industry, caffeine is becoming an emerging pollutant, appearing in surface and ground waters across the world [4], hence the need of caffeine detection from effluents at low concentrations.

Several analytical methods have been developed to detect and quantify caffeine; these methods include several spectrophotometric, chromatographic, and coupled techniques [1]. These latter techniques are often expensive and time-consuming. Thus, the electroanalytical methods appear as an alternative to the traditional analytical methods. Carbon-based electrodes have been used widely for the electrochemical detection of different types of analytes [5-7], including caffeine [8-10]. In recent years, porous carbons have gained attention as potential electrochemical detectors [11,12] mainly due to its large surface area, tunable pore size, and efficient preparation. In this sense, activated carbons are recognized as efficient materials for several applications, and they can be obtained from biomass residues by different activation methods $[13,14]$.

In this work, we used two activated carbons obtained from biomass as electrochemical caffeine sensors. Activated carbons were prepared

\footnotetext{
* Corresponding author

E-mail addresses: jarroyo@unsl.edu.ar (J.J. Arroyo-Gómez), carlosmh@quimica.ufrn.br (C.A. Martínez-Huitle).
} 
Table 1

Experimental conditions to prepare the carbon samples.

\begin{tabular}{lll}
\hline Parameter & $\mathrm{CA}-\mathrm{Zn}$ & $\mathrm{CA}-\mathrm{ZnFe}$ \\
\hline $\begin{array}{l}\text { Activating agent } \\
\text { Impregnation }\end{array}$ & $\mathrm{ZnCl}_{2}$ & $\mathrm{ZnCl}_{2}: \mathrm{FeCl}_{3}(1: 1)$ \\
$\begin{array}{l}\text { Drying } \\
\text { Carbonization }\end{array}$ & $353 \mathrm{~K}, 2 \mathrm{~h}, 12 \mathrm{~h}$ & $353 \mathrm{~K}, 3 \mathrm{~h}$ \\
& $823 \mathrm{~K}, 3 \mathrm{~h}, 10 \mathrm{~K} \mathrm{~min}^{-1}, \mathrm{~N}_{2}$ & $553 \mathrm{~K}, 3 \mathrm{~h}, 10 \mathrm{~K} \mathrm{~min}^{-1}, \mathrm{~N}_{2}$ \\
$\left(100 \mathrm{~mL} \mathrm{~min}^{-1}\right)$ & $\left.(100 \mathrm{~mL} \mathrm{~min})^{-1}\right)$ \\
Washing & $\begin{array}{l}\text { Distillated water at } 323 \mathrm{~K} \\
\text { until } \mathrm{pH}=7.0\end{array}$ & $\begin{array}{l}\text { Distillated water at } 323 \mathrm{~K} \\
\text { until } \mathrm{pH}=7.0\end{array}$ \\
& & \\
\hline
\end{tabular}

and characterized previously. After that, the preparation of electrochemical sensors was carried out by dipping coating method with Nafion. Electrochemical characterization of the modified electrodes was also performed. Finally, caffeinated beverages were used to determine electrochemically the caffeine concentration by using modified electrodes, and the obtained results were close to the reported values for those samples, indicating the possible use of these carbons as an efficient and cheap electrochemical detector.

\section{Materials and methods}

\subsection{Carbon samples preparation}

The activated carbon samples were prepared by chemical activation, using peach stones as the lignocellulosic precursor. The peach stones were milled to obtain a particle size of $2 \mathrm{~mm}$. The activation was performed using $\mathrm{ZnCl}_{2}$ and $\mathrm{ZnCl}_{2}: \mathrm{FeCl}_{3}$ (1:1) (Anedra and Merck) as activating agents. In Table 1 are displayed the conditions employed to produce each carbon.

\subsection{Characterization}

The carbon morphology was studied using a scanning electron microscope (SEM) LEO 1450 VP. The carbon samples were coated with Au $(30 \mathrm{~nm})$, and held to an $\mathrm{Al}$ sample holder using doubled sized carbon tape. The images were taken using a voltage of $15 \mathrm{kV}$.
The textural characterization of the carbons was performed using $\mathrm{N}_{2}$ adsorption-desorption isotherms at $77 \mathrm{~K}$ and $\mathrm{CO}_{2}$ at $273 \mathrm{~K}$. The carbon samples were previously degasified at $523 \mathrm{~K}$ during $24 \mathrm{~h}$. The specific surface area $\left(\mathrm{S}_{\mathrm{BET}}\right)$ was calculated using the BET equation [15]. $\alpha$-Plot, using the $\mathrm{N}_{2}$ adsorption data, was used to calculate the micropore volume $\left(\mathrm{V}_{\mu \mathrm{P}-\mathrm{N} 2}\right)$ and the narrow porosity volume $\left(\mathrm{V}_{\mu \mathrm{P}-\mathrm{CO} 2}\right)[16]$, and Dubinin-Radushkevich from $\mathrm{CO}_{2}$ adsorption data [17], respectively. The total pore volume $\left(\mathrm{V}_{\mathrm{T}}\right)$ was calculated from the adsorbed volume at relative pressure $\left(p / p^{0}\right)$ of 0.98 , according to the Gurvich rule [18].

The $\mathrm{N}_{2}$ adsorption-desorption isotherms were measured in an Autorsorb-1MP sorption analyzer from Quantachrome Instruments. The $\mathrm{CO}_{2}$ adsorption was made in an ASAP 2050 (Micromeritics) sorption analyzer until a pressure of $1000 \mathrm{kPa}$ at $273 \mathrm{~K}$; the samples were previously degasified at $523 \mathrm{~K}$ with reduced pressure during $10 \mathrm{~h}$. The pore size distributions (PSD) were calculated by QSDFT method included in AsiQwin software, v. 4.0 (Quantachrome Instruments) using the Kernel " $\mathrm{N}_{2}$ at $77 \mathrm{~K}$ on carbon (slit pore, QSDFT, equilibrium model)".

The thermogravimetric analysis (TGA) was carried out using an SDT Q600 thermal analyzer from TA Instruments. The samples, ca. $5 \mathrm{mg}$, were heated, under air atmosphere at $50 \mathrm{~mL} \mathrm{~min}^{-1}$, in an alumina pan from room temperature until $800^{\circ} \mathrm{C}$ with a heating rate of $10^{\circ} \mathrm{C} \mathrm{min}{ }^{-1}$. The obtained data were analyzed using the software Universal Analysis 2000 from TA Instruments.

The electrochemical measurements were performed at room temperature with a potentiostat/galvanostat PGSTAT302N (Metrohm Autolab). DPV parameters: initial potential $=0.00 \mathrm{~V}$; final potential $=2.10 \mathrm{~V}$; potential scan rate $=10 \mathrm{mV} \mathrm{s}^{-1}$; scan mode $=$ differential pulse and pulse amplitude $=25 \mathrm{mV}$. The above parameters were used in all measurements. The three-electrode cell consisted of a Pt wire as the counter electrode and an $\mathrm{Ag} / \mathrm{AgCl}_{\text {sat }}$ electrode $(+0.197 \mathrm{~V}$ vs. NHE) as the reference electrode. The working electrode was prepared dispersing $20 \mu \mathrm{L}$ of carbon dispersion over the surface of a polished glassy carbon electrode (GCE) rod (area of $0.78 \mathrm{~cm}^{2}$ ); then, the electrodes were dried at room temperature for $30 \mathrm{~min}$ to ensure the binding between the carbon sample and the glassy carbon support. The carbon dispersion was prepared as follows: $5 \mathrm{mg}$ of the carbon sample was dispersed in $200 \mu \mathrm{L}$ of methanol:Nafion (2:1) mixture with a vortex for $1 \mathrm{~min}$.
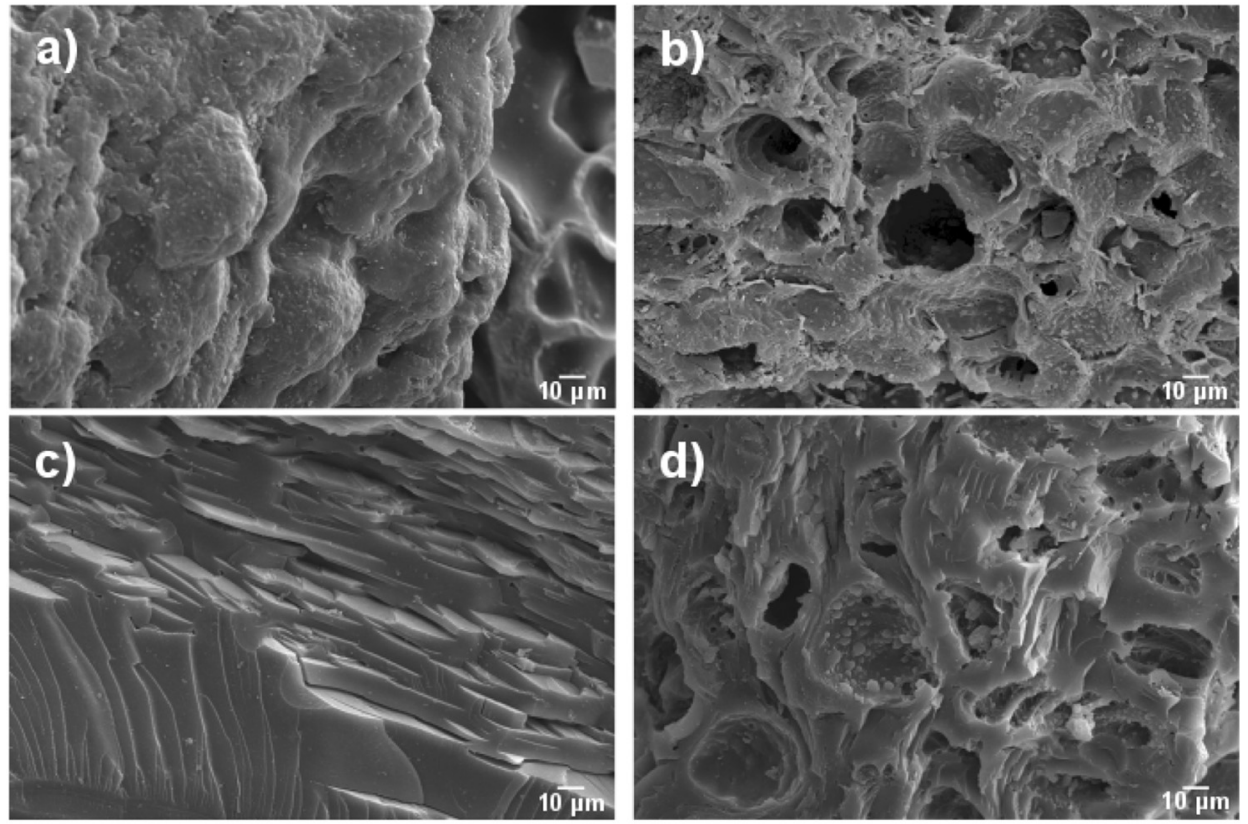

Fig. 1. SEM of CA-Zn (a-b) and CA-ZnFe (c-d) at 500 $\times$. 


\section{Results and discussion}

\subsection{Morphological characterization}

Fig. 1 shows SEM micrographs of the activated carbons. In general, it can be observed that the carbon surfaces are irregular, with roughness, and high porosity, which indicates the possibility of good textural properties. The CA-ZnFe sample (Fig. 1c-d) presents sectors with welldefined bar morphology, composed mainly of flat terraces and few other surface defects that are induced by the activating agent [19]. Meanwhile, the CA-Zn (Fig. 1a-b) presents a more rugged surface morphology; again, the activating agent and method could influence the final morphology of the carbon sample. The chemical analysis and elemental mapping carried out by EDS (Figs. S2 and S3 in the Supplementary Information) revealed that for $\mathrm{CA}-\mathrm{Zn}$, the $\mathrm{Zn}$ content was under the detection limit ( $1 \mathrm{wt} \%$ ); whereas the CA-ZnFe presented 1.19 and $2.29 \mathrm{wt} \%$ of $\mathrm{Zn}$ and $\mathrm{Fe}$, respectively. In CA-ZnFe, iron was only detected in a few grains of the sample, powder XRD analysis (Fig. S4 in Supplementary Information) showed a low-intensity peak at $2 \theta=35^{\circ}$, which could be attributed to $\mathrm{Fe}_{2} \mathrm{O}_{3}$, no other peaks associated to iron compounds were observed, thus indicating that the washing method was effective to remove the activating agents. For both samples, the electrochemical response due to the metallic content is negligible.

\subsection{Textural characterization}

Fig. 2a shows the $\mathrm{N}_{2}$ adsorption-desorption isotherm at $77 \mathrm{~K}$ of the activated carbon samples. It is observed that both samples present microporosity, this can be inferred from the shape of the isotherms, which are type Ib according to the IUPAC classification [20]. Both CA$\mathrm{Zn}$ and CA-ZnFe present a broad knee at low values of relative pressure $\left(p / p^{0}<0.1\right)$, indicating a pore size distribution over a range that includes wider micropores and possibly narrow mesopores $(\sim 2.5 \mathrm{~nm})$ [20]. The pore size distributions (PSD) of the materials are displayed in the Fig. 2b, presenting a similar behavior. The adsorption of $\mathrm{N}_{2}$ and $\mathrm{CO}_{2}$ (inset in Fig. $2 \mathrm{~b}, \mathrm{CO}_{2}$ isotherms at $273 \mathrm{~K}$ are displayed in Fig. S5 in Supplementary Information) shows that both samples have very energetic active sites, with pores in the range of $0.5-1 \mathrm{~nm}$, and $2.2-3.5 \mathrm{~nm}$, respectively.

The textural properties of both carbons are shown in Table 2. It can be observed that the volume of narrow micropores, obtained from $\mathrm{CO}_{2}$ $\left(\mathrm{V}_{\mu \mathrm{P}-\mathrm{CO} 2}\right)$ adsorption data $\left(\mathrm{CO}_{2}\right.$ adsorption isotherm at $273 \mathrm{~K}$ is presented in the Supplementary Information) of the CA-ZnFe sample is lower than the CA-Zn, despite the higher amount of narrow micropores with size near $0.35 \mathrm{~nm}$, that contribute with more energetic sites.

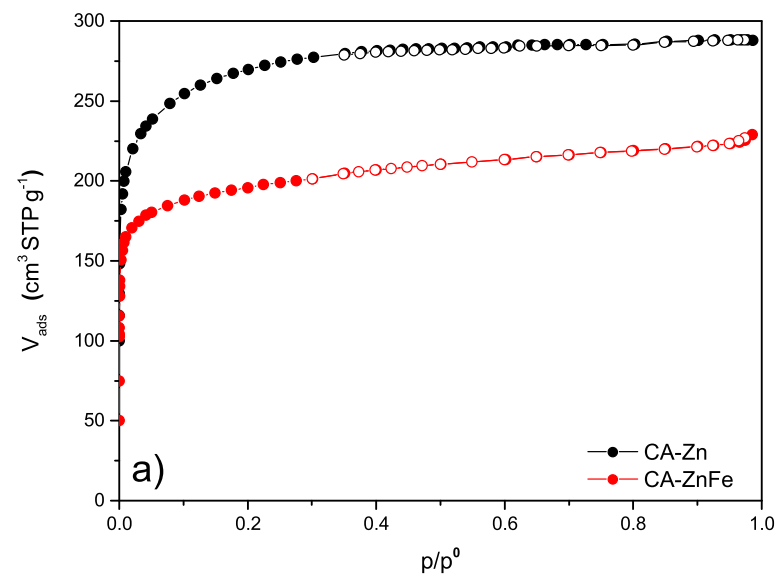

\subsection{Thermogravimetric analysis}

The thermal stability of the carbon samples was tested by thermogravimetric analysis (TGA) under air atmosphere, the results are displayed in Fig. 3, and the obtained data are summarized in Table 3. Both samples present a similar behavior, presenting a single-step weight loss, with total decomposition at ca. $500{ }^{\circ} \mathrm{C}$ and $600{ }^{\circ} \mathrm{C}$, respectively. The CA$\mathrm{Zn}$ presents a rapid decomposition, which starts around $473^{\circ} \mathrm{C}$ and is completed below $600{ }^{\circ} \mathrm{C}$; this eliminates the $97.4 \%$ of the total sample mass, the remaining $2.6 \%$ corresponds to volatile material and gas weakly adsorbed which are eliminated at temperatures lower than $300{ }^{\circ} \mathrm{C}$. On the other hand, the primary decomposition of the CA-ZnFe starts at ca. $336{ }^{\circ} \mathrm{C}$ and finishes below $500{ }^{\circ} \mathrm{C}$, eliminating the $96.4 \%$ of the mass, the other $3.6 \%$ corresponds to weakly adsorbed water which is eliminated below $150{ }^{\circ} \mathrm{C}$. The first derivative of the TGA curves also revealed that the decomposition of the CA-Zn sample is almost $60 \%$ faster than that of CA-ZnFe, but it appears a higher temperature. The differences in both temperature and rate of decomposition are related to the differences in structure and morphology of the carbon samples obtained with the different activating agents; i.e., the activation using the $\mathrm{ZnCl}_{2}: \mathrm{FeCl}_{3}$ mixture produces carbons with a hollow structure, composed of thin walls, thus creating a weak structure [14]. The total decomposition of the both samples corroborates the absence of metallic remaining from the activating agents.

\subsection{Electrochemical characterization}

Due to the porous and hydrophobic nature of the carbon samples, a previous study was carried out to determine the optimal contact time between the electrodes and the caffeine solution. A carbon electrode was immersed in the electrochemical cell containing the solution, and then the system was stirred for several minutes; immediately after specific stirring time a differential pulse voltammetry was performed. This procedure was repeated until obtaining unchanged curves (Fig. S6 Supplementary Information). From this experiment, the optimal contact times between the carbon samples and the working solution were $16 \mathrm{~min}$ and $6 \mathrm{~min}$ for CA-Zn and CA-ZnFe, respectively. These contact times were used for all the subsequent electrochemical experiments.

The active surface areas of the electrodes were estimated using the slope of the $(\mathrm{d} E / \mathrm{dt})^{1 / 2}, I_{\mathrm{p}}$ plot for a given concentration of $\left[\mathrm{Fe}(\mathrm{CN})_{6}\right]^{-3}$ (Fig. S7 in Supporting Information). According to Randles-Sevcik equation [21]:

$I_{p}=2.69 \times 10^{5} n^{3 / 2} A D^{1 / 2} v^{1 / 2} C$

where $I_{\mathrm{p}}$ is the anodic peak current, $n$ the electron transfer number, $A$ the electrode surface area, $D$ the diffusion coefficient, $C$ the

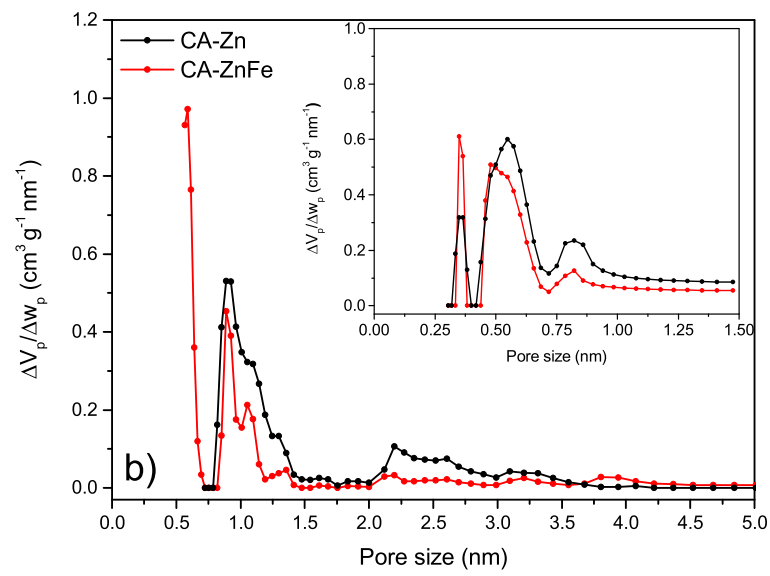

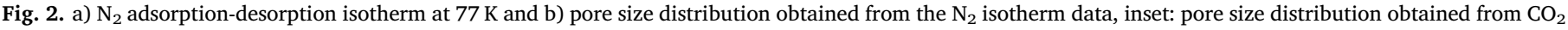
adsorption data. 
Table 2

Textural properties of the carbon materials.

\begin{tabular}{|c|c|c|c|c|c|c|}
\hline \multirow[t]{2}{*}{ Sample } & \multicolumn{5}{|c|}{$\mathrm{N}_{2}$ adsorption at $77 \mathrm{~K}$} & \multirow{2}{*}{$\begin{array}{l}\mathrm{CO}_{2} \text { adsorption at } 273 \mathrm{~K} \\
\mathrm{~V}_{\mu \mathrm{P}-\mathrm{CO} 2} \\
\left(\mathrm{~cm}^{3} \mathrm{~g}^{-1}\right)\end{array}$} \\
\hline & $\begin{array}{l}\mathrm{S}_{\mathrm{BET}} \\
\left(\mathrm{m}^{2} \mathrm{~g}^{-1}\right)\end{array}$ & $\begin{array}{l}\mathrm{S}_{\mathrm{EXT}} \\
\left(\mathrm{m}^{2} \mathrm{~g}^{-1}\right)\end{array}$ & $\begin{array}{l}\mathrm{V}_{\mu \mathrm{P}-\mathrm{N} 2} \\
\left(\mathrm{~cm}^{3} \mathrm{~g}^{-1}\right)\end{array}$ & $\begin{array}{l}\mathrm{V}_{\mathrm{MP}}{ }^{\mathrm{a}} \\
\left(\mathrm{cm}^{3} \mathrm{~g}^{-1}\right)\end{array}$ & $\begin{array}{l}V_{T} \\
\left(\mathrm{~cm}^{3} \mathrm{~g}^{-1}\right)\end{array}$ & \\
\hline CA-Zn & 1020 & 104 & 0.38 & 0.07 & 0.45 & 0.32 \\
\hline CA-ZnFe & 760 & 125 & 0.25 & 0.10 & 0.35 & 0.19 \\
\hline
\end{tabular}

${ }^{\mathrm{a}} \mathrm{V}_{\mathrm{MP}}=\mathrm{V}_{\mathrm{T}}-\mathrm{V}_{\mu \mathrm{P}-\mathrm{N} 2}$.

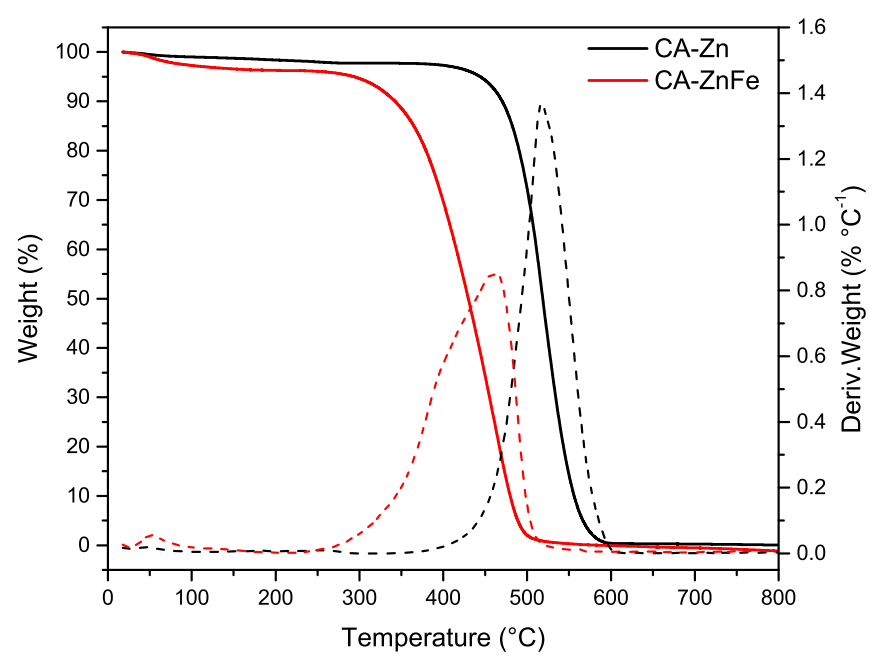

Fig. 3. TGA - DTG curves of the carbon samples. Continuous line: TGA, dotted line: DTG.

Table 3

Weight loss data from the TGA-DTA curves.

\begin{tabular}{lllll}
\hline Sample & $\begin{array}{l}\text { Total weight loss } \\
(\%)\end{array}$ & $\begin{array}{l}\mathrm{T}_{\text {onset }} \\
\left({ }^{\circ} \mathrm{C}\right)\end{array}$ & $\begin{array}{l}\text { Integration interval } \\
\left({ }^{\circ} \mathrm{C}\right)\end{array}$ & $\begin{array}{l}\text { Weight loss } \\
(\%)\end{array}$ \\
\hline CA-Zn & 100 & 473.4 & $350-650$ & 97.4 \\
CA-ZnFe & 100 & 336.2 & $\begin{array}{l}27-200 \\
210-600\end{array}$ & $\begin{array}{l}3.6 \\
96.4\end{array}$ \\
& & & &
\end{tabular}

concentration of $\left[\mathrm{Fe}(\mathrm{CN})_{6}\right]^{-3}$, and $v$ is the scan rate $(\mathrm{d} E / \mathrm{dt})$. From the experimental data, $n=1$, and considering $D=7.6 \times 10^{-6} \mathrm{~cm}^{2} \mathrm{~s}^{-1}$ [22], the estimated areas of the electrodes were $0.005 \mathrm{~cm}^{2}$ and $0.018 \mathrm{~cm}^{2}$ for CA-Zn and CA-ZnFe, respectively. These values are similar to the reported elsewhere for porous carbons used as sensors $[11,12]$. As a preliminary idea, the results showed that CA-ZnFe

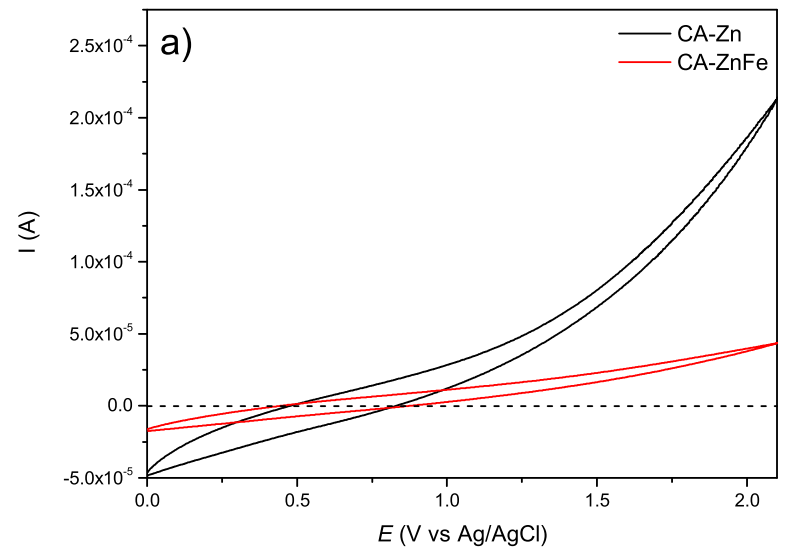

presents a higher electrochemical response for electroactive species in solution.

The electrochemical behavior of the carbon samples was tested using cyclic voltammetry, and the results are displayed in Fig. 4. In the supporting electrolyte (Fig. 4a), the activated carbons did not exhibit cathodic or anodic peaks. In presence of caffeine (Fig. 4b) both samples present a weak anodic peak at ca. $1.5 \mathrm{~V}$ that corresponds to caffeine oxidation; this peak presents a higher current in the CA-ZnFe sample. In the working solution, both GCE and Nafion-modified GCE (see Fig. S8 in Supporting Information) presented higher currents towards caffeine oxidation when compared to the activated carbon electrodes. No cathodic peaks were observed, indicating that caffeine oxidation is irreversible; this behavior is in agreement with the results reported elsewhere $[8,23,24]$. The oxidation mechanism is a $4 \mathrm{e}^{-}, 4 \mathrm{H}^{+}$process, in which are formed intermediates such as uric acid, and its diol-analog, that fragment rapidly [23,25].

The sensitivity of the carbon electrodes was tested by differential pulse voltammetry (Fig. 5); the relevant parameters of this experiment are reported in the material and methods section. As previously observed in cyclic voltammetry, both electrodes present a similar electrochemical behavior, where CA-ZnFe showed the highest activity towards caffeine oxidation. This behavior is related to the higher active area of CA-ZnFe, as it was estimated before.

A linear relationship between the peak current and caffeine concentration was obtained analyzing caffeine solutions in acidic media; the results are shown in the insets of Fig. 5a and b. The calibration curves for caffeine were obtained for each electrode; each curve was obtained evaluating the peak intensity as a function of caffeine concentration and considering seventeen analyte concentrations. For the CA-Zn electrode (inset Fig. 5a) the linear response was from $3.98 \times 10^{-5}$ to $4.58 \times 10^{-4} \mathrm{M}\left(r^{2}=0.995\right)$; whereas for CA-ZnFe (Fig. 5b), the linear range was from $3.98 \times 10^{-5}$ to $6.37 \times 10^{-4} \mathrm{M}$ $\left(r^{2}=0.995\right)$. The slight deviation from linearity observed in the CA-Zn electrode from $4.94 \times 10^{-4} \mathrm{M}$ can be attributed to the incipient electrode saturation, which is gradual due to the low increments of caffeine concentration after each addition. The changes in both slope and intercepts can be due to the different carbon surfaces. Using the standard

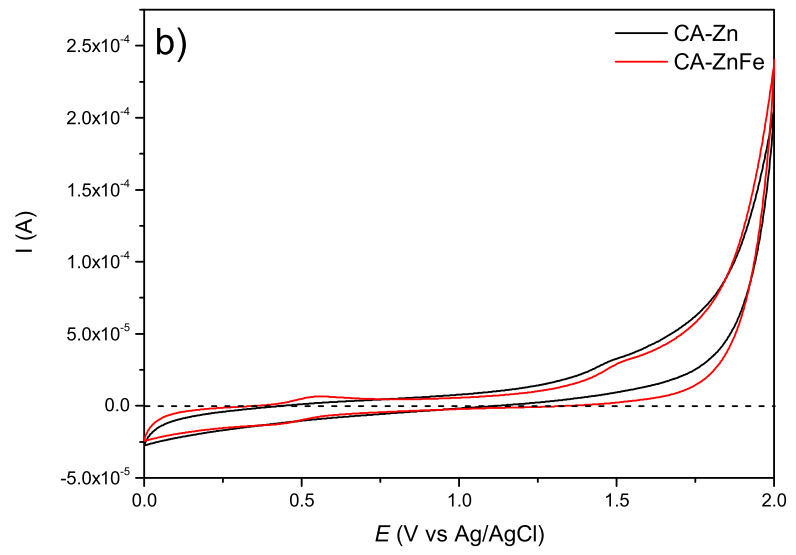

Fig. 4. Cyclic voltammogram of activated carbons in: a) $1 \mathrm{M} \mathrm{H}_{2} \mathrm{SO}_{4}$ and b) $0.01 \mathrm{M}$ caffeine $+1 \mathrm{M} \mathrm{H}_{2} \mathrm{SO}_{4} \cdot|\mathrm{d} E / \mathrm{dt}|=100 \mathrm{mV} \mathrm{s}{ }^{-1}$. 

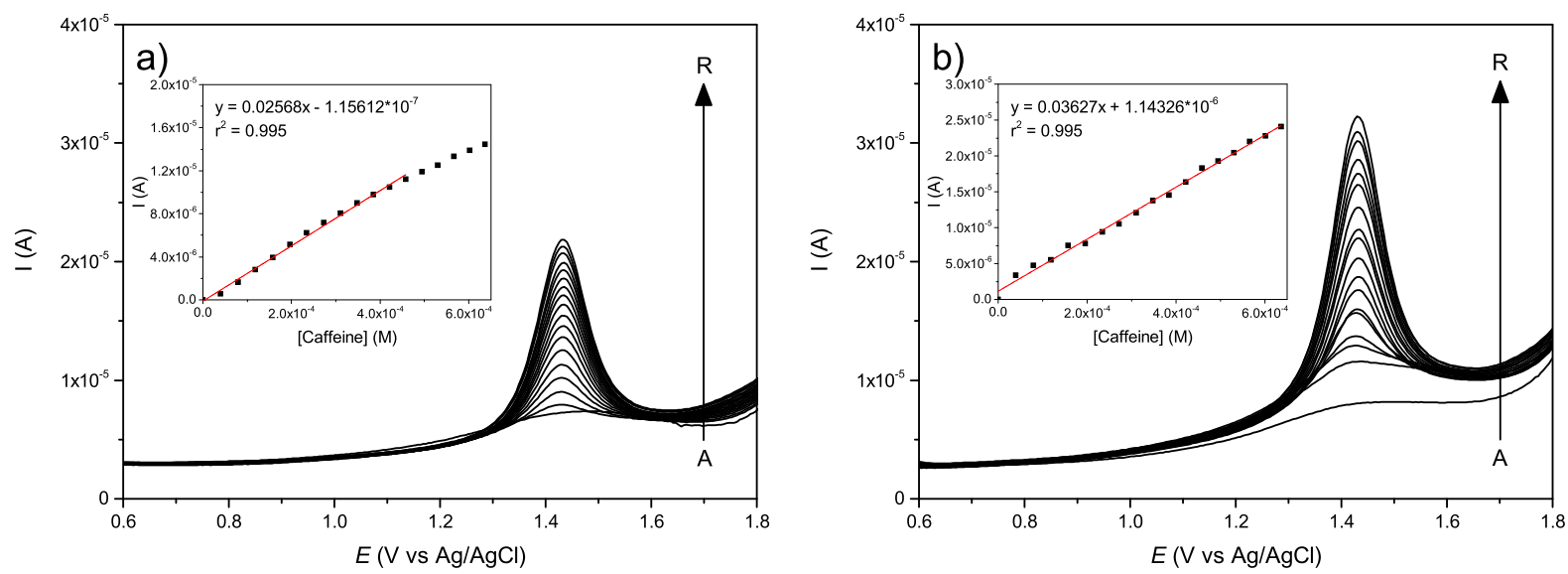

Fig. 5. Differential pulse voltammograms of a) CA-Zn and b) CA-ZnFe electrodes in acidic media $\left(1 \mathrm{M} \mathrm{H}_{2} \mathrm{SO}_{4}\right)$. Standard additions of caffeine solution (0.01 M), concentrations from $\mathrm{A}$ to $\mathrm{R}$ in the following order: supporting electrolyte, $3.98 \times 10^{-5}, 7.93 \times 10^{-5}, 1.18 \times 10^{-4}, 1.57 \times 10^{-4}, 1.96 \times 10^{-4}, 2.34 \times 10^{-4}$, $2.72 \times 10^{-4}, 3.10 \times 10^{-4}, 3.47 \times 10^{-4}, 3.85 \times 10^{-4}, 4.21 \times 10^{-4}, 4.58 \times 10^{-4}, 4.94 \times 10^{-4}, 5.30 \times 10^{-4}, 5.66 \times 10^{-4}, 6.01 \times 10^{-4}$, and $6.37 \times 10^{-4}$. Inset: linear plot of caffeine concentration versus peak current.

Table 4

Caffeine content measured using the activated carbon electrodes.

\begin{tabular}{llllll}
\hline Sample & \multicolumn{2}{l}{ Measured caffeine concentration (M) } & & \multicolumn{2}{l}{ Reported concentration ${ }^{\mathrm{a}}$} \\
\cline { 2 - 3 } \cline { 5 - 6 } & Coca-Cola (M) & Pepsi (M) & & Coca-Cola (M) & Pepsi (M) \\
\hline CA-Zn & $2.23 \times 10^{-4}$ & $3.63 \times 10^{-4}$ & & $4.93 \times 10^{-4}$ & $5.52 \times 10^{-4}$ \\
CA-ZnFe & $5.01 \times 10^{-4}$ & $5.15 \times 10^{-4}$ & & \\
\hline
\end{tabular}

${ }^{\text {a }}$ Obtained from the nutritional chart provided by the manufacturers. Coca-Cola: $2.83 \mathrm{mg}$ per fl. oz.

Pepsi: $3.17 \mathrm{mg}$ per fl. oz.

deviation of regression, the limit of detection (LOD) was calculated as follows [24]:

$L O D=3 \times \frac{S_{y / x}}{b}$

where $S_{\mathrm{y} / \mathrm{x}}$ is the residual standard deviation and $b$ is the slope of the calibration curve. Based on the results here obtained, the LOD calculated for CA-Zn and CA-ZnFe were $2.85 \times 10^{-5}$ and $1.60 \times 10^{-5} \mathrm{M}$, respectively.

Electrochemical tests were performed on real caffeine-containing samples using the activated carbon modified electrodes. The standard addition method was chosen to minimize the matrix effect that may appear due to the presence of the different components of the studied samples. Before each analysis, the samples were degasified by ultrasonication; after that, the sample was diluted in the supporting electrolyte $\left(1 \mathrm{M} \mathrm{H}_{2} \mathrm{SO}_{4}\right)$ to operate within the linear range of the method. The measured data are displayed in Table 4, and it can be concluded that the carbon samples are sensitive to caffeine, showing higher current signals when solutions with higher contents of the analyte were analyzed. The CA-ZnFe sample measured caffeine concentrations similar to those reported in a previous work [24,26], in which HPLC is used as an independent method $\left(7.2 \times 10^{-4} \mathrm{M}\right.$ and $5.5 \times 10^{-4} \mathrm{M}$ were the caffeine concentrations for the samples used in this work (Coca-Cola and Pepsi), respectively). These results are also in good agreement with the reported by several authors using different analytical tools such as FTIR [27], HPLC [28-39], UV-vis [27,29], and electrochemical determinations $[29,30]$ as well. The caffeine concentrations measured with the CA-ZnFe electrode are comparable to those reported in the nutritional chart of the beverages. Finally, a caffeine-free sample (Sprite) was also analyzed, and the obtained results were very close to zero. A more detailed study is still required to improve the sensitivity of the electrodes; however, the reported results indicate the possibility of using these samples as reliable sensors.

\section{Conclusions}

We were able to obtain simple caffeine sensors based on activated carbon from biomass. The different activation methods to obtain the carbon material, allowed us to obtain materials with different textural properties, which affected the electrochemical response. Under the studied conditions, both samples exhibited a linear behavior and low detection limits. However, the carbon sample obtained with $\mathrm{ZnCl}_{2}: \mathrm{FeCl}_{3}$ (1:1) presented the highest sensitivity; this may be due to morphology, low roughness, and texture, with ultramicropores, which contribute to more energetic adsorption sites and mesopores that can facilitate the mobility of the caffeine molecules. These properties provide a higher number of active sites (i.e., active area) towards caffeine oxidation. Beverages containing caffeine were analyzed, and the results obtained with CA-ZnFe are near the reported values.

To improve the performance of the electrodes, further studies are still required. Nonetheless, our results indicate the potential of these electrodes for future application in electrochemical sensors for food and environmental applications.

\section{Acknowledgments}

The authors want to thank UNSL and UFRN for the financial support of this work. J.J. Arroyo-Gómez acknowledges the fellowships granted by ANPCyT and CAPES-SPU. D. Villarroel-Rocha acknowledges the doctoral fellowship granted by CONICET. C.A. Martínez-Huitle acknowledges the financial support from projects CNPq - 465571/20140 , CNPq - 446846/2014-7, CNPq - 401519/2014-7, and FAPESP 2014/50945-4.

\section{Appendix A. Supplementary data}

Supplementary data to this article can be found online at https:// doi.org/10.1016/j.jelechem.2018.05.028.

\section{References}

[1] S. Oestreich-Janzen, Caffeine: characterization and properties, in: B. Caballero, P.M. Finglas, F. Toldrá (Eds.), Encyclopedia of Food and Health, Academic Press, Oxford, 2016, pp. 556-572, , http://dx.doi.org/10.1016/B978-0-12-384947-2. 00098-2.

[2] S. Gaspar, F. Ramos, Caffeine: consumption and health effects, in: B. Caballero, 
P.M. Finglas, F. Toldrá (Eds.), Encyclopedia of Food and Health, Academic Press, Oxford, 2016, pp. 573-578, , http://dx.doi.org/10.1016/B978-0-12-384947-2. 00099-4.

[3] T.M. Mclean, J.A. Caldwell, H.R. Liebermann, A review of caffeine's effects on cognitive, physical and occupational performance, Neurosci. Biobehav. Rev. 71 (2016) 294-312, http://dx.doi.org/10.1016/j.neubiorev.2016.09.001.

[4] M.T. Moore, S.L. Greenway, J.L. Farris, B. Guerra, Assessing caffeine as an emerging environmental concern using conventional approaches, Arch. Environ. Contam. Toxicol. 54 (2008) 31-35, http://dx.doi.org/10.1007/s00244-007-9059-4.

[5] S. Kurbanoglu, S.A. Oskan, Electrochemical carbon based nanosensors: a promising tool in pharmaceutical and biomedical analysis, J. Pharm. Biomed. Anal. 147 (2018) 439, http://dx.doi.org/10.1016/j.jpba.2017.06.062.

[6] C. Yang, M.E. Denno, P. Pyakurel, B.J. Venton, Recent trends in carbon nanomaterial-based electrochemical sensors for biomolecules: a review, Anal. Chim. Acta 887 (2015) 17-37, http://dx.doi.org/10.1016/j.aca.2015.05.049.

[7] P. Veerakumar, V. Veeramani, S.M. Chen, R. Madhu, S.B. Liu, Palladium nanoparticle incorporated porous activated carbon: electrochemical detection of toxic metal ions, ACS Appl. Mater. Interfaces 8 (2016) 1319-1326, http://dx.doi.org/10 1021/acsami.5b10050.

[8] A.C. Torres, M.M. Barsan, C.M.A. Brett, Simple electrochemical sensor for caffeine based on carbon and Nafion-modified carbon electrodes, Food Chem. 149 (2014) 215-220, http://dx.doi.org/10.1016/j.foodchem.2013.10.114.

[9] M. Amare, S. Aklog, Electrochemical determination of caffeine content in ethiopian coffee samples using lignin modified glassy carbon electrode, J. Anal. Methods Chem. 2017 (2017), http://dx.doi.org/10.1155/2017/3979068.

[10] B. Bruneti, E. Desimoni, P. Casati, Determination of caffeine at a Nafion-covered glassy carbon electrode, Electroanalysis 19 (2007) 385-388, http://dx.doi.org/10. 1002/elan.200603679.

[11] Q. Cheng, L. Ji, K. Wu, W. S, Morphology-dependent electrochemical enhancements of porous carbon as sensitive determination platform for ascorbic acid, dopamine and uric acid, Sci. Rep-UK 6 (2016), http://dx.doi.org/10.1038/srep22309.

[12] B. Thakur, X. Guo, J. Chang, M. Kron, J. Chen, Porous carbon and Prussian blue composite: a highly sensitive electrochemical platform for glucose biosensing, Sens. Biosens. Res. 14 (2017) 47-53, http://dx.doi.org/10.1016/j.sbsr.2017.05.002.

[13] D.A. Soares Maia, J.C. Alexandre de Oliveira, J.P. Tosso, K. Sapag, R.H. Lopez, D.C.S. Azevedo, C.L. Cavalcante Jr., G. Zgrablich, Characterization of the PSD of activated carbons from peach stones for separation of combustion gas mixtures, Adsorption 17 (2011) 853-861, http://dx.doi.org/10.1007/s10450-011-9344-4.

[14] L.C.A. Oliveira, E. Pereira, I.R. Guimaraes, A. Vallone, M. Pereira, J.P. Mesquita, K. Sapag, Preparation of activated carbons from coffee husks utilizing $\mathrm{FeCl}_{3}$ and $\mathrm{ZnCl}_{2}$ as activating agents, J. Hazard. Mater. 165 (2009) 87-94, http://dx.doi.org/ 10.1016/j.jhazmat.2008.09.064.

[15] S. Brunauer, P.H. Emmet, E. Teller, Adsorption of gases in multimolecular layers, J. Am. Chem. Soc. 60 (1938) 309-319, http://dx.doi.org/10.1021/ja01269a023.

[16] S.J. Gregg, K.S.W. Sing, Adsorption, Surface Area and Porosity, Second edition, Academic Press, London, 1982.

[17] M.M. Dubinin, The potential theory of adsorption of gases and vapors for ad sorbents with energetically nonuniform surfaces, Chem. Rev. 60 (1960) 235-241, http://dx.doi.org/10.1021/cr60204a006.

[18] F. Rouquerol, J. Rouquerol, K. Sing, Adsorption by Powders and Porous Solids: Principles, Methodology and Applications, Academic Press, San Diego, 1998.

[19] V. Hernández-Montoya, J. García-Servin, J.I. Bueno-López, Thermal treatments and activation procedures used in the preparation of activated carbons, in: V. Hernández-Montoya, A. Bonilla-Petriciolet (Eds.), Lignocellulosic Precursors Used in the Synthesis of Activated Carbon - Characterization Techniques and Applications in the Wastewater Treatment, inTech, 2012, pp. 19-36.

[20] M. Thommes, K. Kaneko, A.V. Neimark, J.P. Olivier, F. Rodriguez-Reinoso, J. Rouquerol, K.S.W. Sing, Physisorption of gases, with special reference to the evaluation of surface area and pore size distribution (IUPAC Technical Report), Pure Appl. Chem. 87 (2015) 1051-1069, http://dx.doi.org/10.1515/pac-2014 1117.

[21] W.A. Bott, B.P. Jackson, Study of ferricyanide by cyclic voltammetry using the CV50W, Curr. Sep. 15 (1996) 25-30.

[22] A. Purwidyantri, C.-H. Chen, L.-Y. Chen, C.-C. Chen, J.-D. Luo, C.-C. Chiou, Y.C. Tian, C.-Y. Lin, C.-M. Yang, H.-C. Lai, C.-S. Lai, Speckled ZnO nanograss electrochemical sensor for Staphylococcus epidermidis detection, J. Electrochem. Soc. 164 (2017) B205-B211, http://dx.doi.org/10.1149/2.0811706jes.

[23] N. Spataru, B.V. Sarada, D.A. Tryk, A. Fukushima, Anodic voltammetry of xanthine, theophylline, theobromine and caffeine at conductive diamond electrodes and its analytical application, Electroanalysis 14 (2002) 721-728, http://dx.doi.org/10. 1002/1521-4109(200206)14:11 < 721::AID-ELAN721 > 3.0.CO;2-1.

[24] C.A. Martinez-Huitle, N. Suely Fernandes, S. Ferro, A. De Battisti, M.A. Quiroz, Fabrication and application of Nafion ${ }^{\circledR}$-modified boron-doped diamond electrode sensor for detecting caffeine, Diam. Relat. Mater. 19 (2010) 1188-1193, http://dx doi.org/10.1016/j.diamond.2010.05.004.

[25] A.R.L. da Silva, D.M. de Araújo, E.B.S. da Silva, D. Serradella Vieira, N.K. Vieira Monteiro, C.A. Martínez-Huitle, Understanding the behavior of caffeine on a borondoped diamond surface: voltammetric, DFT, QTAIM and ELF studies, New J. Chem. 41 (2017) 7766-7774, http://dx.doi.org/10.1039/C7NJ00386B.

[26] D.M. de Araújo, C. do Nascimento Brito, S.D.S. de Oliveira, D.R. da Silva, C.A. Martínez-Huitle, C.F.S. Aragão, Platinum sensor for quantifying caffeine in drug formulations, Curr. Pharm. Anal. 10 (2014) 231-238, http://dx.doi.org/10. 2174/1573412910666140630191329.

[27] M.M. Paradkar, J. Irudayaraj, Rapid determination of caffeine content in soft drinks using FTIR-ATR spectroscopy, Food Chem. 78 (2002) 261-266, http://dx.doi.org/ 10.1016/S0308-8146(02)00116-4.

[28] M.M. Ali, M. Eisa, M.I. Taha, Determination of caffeine in some Sudanese beverages by high performance liquid chromatography, Pak. J. Nutr. 11 (2012) 336-342, http://dx.doi.org/10.3923/pjn.2012.336.342.

[29] J.-Y. Sun, K.-J. Huang, S.Y. Wei, Z.-W. Wu, F.-P. Ren, A graphene-based electrochemical sensor for sensitive determination of caffeine, Colloids Surf. B 84 (2011) 421-426, http://dx.doi.org/10.1016/j.colsurfb.2011.01.036.

[30] L. Švorc, P. Tomčik, J. Svítaková, M. Rievaj, D. Bustin, Voltammetric determination of caffeine in beverage samples on bare boron-doped diamond electrode, Food Chem. 135 (2012) 1198-1204, http://dx.doi.org/10.1016/j.foodchem.2012.05. 052 